\title{
Transcatheter aortic valve replacement: Are we ready to expand the use?
}

\author{
Oscar A. Mendiz \\ Cardiology and Cardiovascular Surgery Institute, Favaloro Foundation University Hospital, \\ Buenos Aires, Argentina
}

Surgical aortic valve replacement (SAVR) has been a standard of care for patients with severe aortic stenosis (SAS) with excellent procedural outcomes, low complication rates and acceptable valve durability when bioprostheses were used. However, many patients with SAVR indication did not undergo surgery worldwide due to high surgical risk or many other not well-known reasons [1].

Moreover, outstanding surgical outcomes cannot be replicated in every single center doing SAVR around the globe.

Transcatheter aortic valve replacement (TAVR) was introduced by Dr Cribier, as an alternative to extreme risk patients 14 years ago [2]. After initial development, TAVR was tested against the standard treatment for inoperable patients and SAVR in well-conducted randomized clinical trials; using the 2 most studied currently available TAVR devices.

Out of these trials we have learned that TAVR is superior to medical treatment including balloon aortic valvuloplasty for inoperable patients. It is necessary to treat only 5 patients to save 1 life within a year. Thus, TAVR becomes a standard treatment for anatomically suitable patients suffering from symptomatic SAS [3, 4].

For those patients with life expectancy shorter than 1-year or extremely deteriorated physical condition precluding benefit from TAVR, the concept of futility was introduced [5]. With that, a new concern has arisen, and patients requiring TAVR should be excluded from this treatment because a poor benefit is expected based on the heart team evaluation.

TAVR was also tested in those patients with high surgical risk in 2 randomized clinical trials
(RCT) showing similar outcomes to SAVR in the PARTNER trial and superiority in the US Pivotal CoreValve study. After these outcomes were presented TAVR was considered an alternative to SAVR for this population, the high cost being the main limitation for its wide use in most countries $[6,7]$.

Although TAVR was initially introduced for high-risk patients, many intermediate risk cases were treated and reported worldwide. Meanwhile, 2 big RCT (PARTNER II and SURTAVI trial) were conducted [8]. Also, there are several registries and matched comparisons showing that TAVR has better outcomes in these groups of patients, which are similar and better than SAVR in some cases. The lower the risk, the better the outcomes.

In this regard, the NOTION trial evaluated a combined primary endpoint including any death, myocardial infarction or stroke at 1 year, which was similar for TAVR and SAVR (13.1\% vs. $16.3 \%$; $\mathrm{p}=0.43)$. SAVR-treated patients had more major bleeding, new onset atrial fibrillation and cardiogenic shock, while TAVR patients had more aortic regurgitation and they need more permanent pacemaker implantation.

However, there is still no consensus about treating these intermediate risk patients in the routine clinical practice, especially when young. Nevertheless, different subgroups may be considered among them, being the octogenarians without other co-morbidities; probably the first subset that may benefit from the TAVR use expansion, because initial outcomes have been probed and durability is no longer an issue for this population, after 5 -year follow-ups have been reported.

Beyond big RCT there are several series and registries reflecting the real life practice and show-

Address for correspondence: Oscar A. Mendiz, MD, FACC, FSCAI, Chairman of Cardiology and Cardiovascular Surgery Institute Board of Directors, Favaloro Foundation University Hospital, (C1093AAS) Belgrano 1746 - $4^{\circ}$ Piso, Ciudad Autónoma de Buenos Aires, Argentina, tel: (54 11) 4378-1359, fax: (54 11) 4378-1361, e-mail: omendiz@ffavaloro.org 
ing quite similar outcomes with those found in the aforementioned randomized clinical studies [9-11].

Device durability has been a concern issue from the beginning of the experience, but we have now some data in this regard to downgrade this concern. PARTNER 5-year follow-up showed consistence on outcomes over time, despite the high mortality rate observed in both groups mainly due to baseline conditions in the inoperable group (mean survival was 11.1 months for standard therapy and 29.7 months for TAVR treatment; $\mathrm{p}<0.0001)$. Re-hospitalization was also higher in the standard treatment arm. The 5-year survival in the PARTNER A group was 40.6 months for SAVR and 44.5 months for TAVR group; $\mathrm{p}=\mathrm{NS}$ [12]. A recently published 2-year follow-up of the CoreValve US Pivotal showed even better outcomes compared with 1-year, because there was an increase in the reduction of mortality from $1^{\text {st }}$ to $2^{\text {nd }}$ years of the follow-up (4.9 to 6.5 percentage points) in favor of TAVR compared with the surgical arm and becoming significant $(\mathrm{p}=0.04)$. A similar continued divergence was seen in the stroke rates of $6.5 \%$ at 1 year to $8.9 \%$ at 2 years [13].

An Italian multicenter registry including 353 patients who received a third-generation CoreValve with a 5-year follow-up showed similar mortality rate to RCT; a late prosthesis failure occurred in $1.4 \%$ of cases. Ten $(2.8 \%)$ patients showed late mild stenosis with a mean transaortic gradient ranging from 20 to $40 \mathrm{~mm} \mathrm{Hg}$ [14].

This low valve deterioration rate over the 5-7 years is in agreement with other presentations. However, there are many pending questions, such as: can these outcomes be considered a class effect?; are they similar to different vascular access?; and, would be these outcomes similar to new devices that are being introduced on the market?

Regarding periprocedural complications, the higher stroke rate observed in the TAVR group of the PARTNER trial was worrisome [15]. However, those findings were not corroborated by the US Pivotal study using the self-expanding device. Moreover, stroke rate was lower in the TAVR group, and for some not well-explained reasons this difference was wider at $2^{\text {nd }}$ year favoring TAVR. In the same way, all registries were showing a trend for better clinical outcomes and lower complications rate, including stroke - probably due to more experienced operators and better devices [16].

Furthermore, a multicenter registry using CoreValve without pre-dilation showed lower stroke rate in comparison to those patients who received valvuloplasty before device implantation showing that technique is also important. In our series of CoreValve cases without pre-dilation $(\mathrm{n}=165)$, we have an any stroke rate of $2.4 \%$ (1.2\% major stroke). Additionally, some studies using cerebral protection devices and subrogate endpoints showed promising findings regarding less micro- and macro-embolization when cerebral protection was used [17-20].

It is also important to know that preoperative neurocognitive status seems to be kept at 2 years after TAVR [21].

With a better technique, the need of PPM implantation has been reduced but still remains high for self-expanding device. The good news is that PPM implantation after TAVR does not have clinical consequences on long-term follow-up with the self-expandable valve and most of the registries; but not in a subanalysis of the PARTNER trial, which showed longer hospital stay, more re-hospitalization and mortality for those who received PPM [22].

New devices with lower profile, refinement on patient selection and more experienced operators may decrease vascular complication, one of the major predictors of perioperative mortality in the initial series, leading also the femoral approach to be the most commonly used by far in the current practice.

Thus, femoral approach using closure devices paved the way to use local anesthesia under sedation or neuroleptoanalgesia, transthoracic echo guidance with provisional transesophageal echocardiography for a so called "minimalist strategy"; decreasing patients trauma caused the procedure [23, 24].

Residual aortic regurgitation was found to be a strong predictor of late mortality, not only for severe but also for moderate insufficiency. However, the number of patients with severe residual paravalvular leak has decreased because a better patient and device selection, technique and device improvement and also because all operators are aware of the importance of this fact and make all the effort to fix it during the index procedure [25, 26].

Different subgroups of patients have been analyzed with the aim of finding those who can benefit more from the TAVR strategy. Among them, diabetics did better with TAVR, they had a lower 1-year mortality rate (18\% vs. $27.4 \%$, hazard ratio: 0.60 ; $95 \%$ confidence interval [CI]: 0.36-0.99; $\mathrm{p}=0.04$ ) with a lower incidence of dialysis $>30$ days ( $0 \%$ vs. $6.1 \%$; $\mathrm{p}=0.003)$ without any differences in the stroke rate (PARTNER) [1].

Female gender showed lower 1-year mortality rate with TAVR in the PARTNER trial [27]. 
Overweight patients also seem to benefit from TAVR vs. SAVR.

Concomitant mitral regurgitation is a frequent comorbid condition to SAS that usually tends to decrease after TAVR, but in some cases it does not occur and can also be a strong predictor of early (odds ratio [OR]: $1.49,95 \%$ CI: $1.12-2.00 ; \mathrm{p}=$ $=0.004$; heterogeneity test $=0.006)$ and late $(\mathrm{OR}$ : 1.44, 95\% CI: 1.23-1.68; $\mathrm{p}<0.001$; heterogeneity test $=0.019$ ) post-procedural mortality, which is higher in those patients who also have low left ventricular ejection fraction and low gradient: $11.5 \%$ vs. $38.1 \%$; adjusted hazard ratio: $3.27 ; 95 \%$ CI: $1.31-8.15 ; \mathrm{p}=0.011$ and adjusted hazard ratio: $4.62 ; \mathrm{p}=0.005[18,19]$. Moreover, patients with SAS and mitral regurgitation included in the PARTNER trial had a higher mortality rate at follow-up with isolated SAVR in comparison with TAVR without mitral valve repair or replacement [28].

With all this information, which is daily updated, we have enough data to support TAVR indication as the first strategy for patients with surgical contraindication and also to consider TAVR an excellent alternative to SAVR in patients at risk but who can be operated according to the Heart Team evaluation keeping in mind that SAVR perioperative mortality should not be higher than $3-4 \%$. Thus, intermediate risk patients should be kept as a potential alternative, meanwhile the procedure is still highly expensive and RCTs in this regard are still not presented. However, some subgroup of intermediate risk patients should be now deeply discussed within the Heart Team, because some would benefit and should not face the risk of surgery.

In this regard, I would like to draw the attention to the octogenarians, especially those requiring combined surgery (CABG + SAVR). These patients may benefit from percutaneous coronary intervention and staged TAVR.

Women, especially those with small body surface and small left ventricular outflow tract and severe overweight patients may be the second group for TAVR use expansion.

However, despite all this excitement, we have to be cautious about long-term durability (> 8-9 years), whereas long waiting list of high risk patients are still waiting health insurance authorization, and some time dying, in many centers worldwide.

Finally, minimalist approach should not overpass the need of a multidisciplinary team and a high volume center so that, the RCT and big series' outcomes are replicated to justify a still very expensive technique to be used in more patients.
Conflict of interest: Medtronic (consultatnt) level = significant; AstraZeneca (consultant) level $=$ modest .

\section{References}

1. Iung B, Baron G, Butchart EG et al. A prospective survey of patients with valvular heart disease in Europe: The Euro Heart Survey on Valvular Heart Disease. Eur Heart J, 2003; 24: 1231-1243 .

2. Cribier A, Eltchaninoff H, Bash A et al. Percutaneous transcatheter implantation of an aortic valve prosthesis for calcific aortic stenosis: First human case description. Circulation, 2002; 106: 3006-3008.

3. Leon MB, Smith CR, Mack M et al. PARTNER Trial Investigators. Transcatheter aortic-valve implantation for aortic stenosis in patients who cannot undergo surgery. N Engl J Med, 2010; 363: 1597-1607. doi: 10.1056/NEJMoa1008232.

4. Popma JJ, Adams DH, Reardon MJ et al. CoreValve United States Clinical Investigators. Transcatheter aortic valve replacement using a self-expanding bioprosthesis in patients with severe aortic stenosis at extreme risk for surgery. J Am Coll Cardiol, 2014; 63: 1972-1981. doi: 10.1016/j.jacc.2014.02.556.

5. Lindman BR, Alexander KP, O'Gara PT, Afilalo J. Futility, benefit, and transcatheter aortic valve replacement. J Am Coll Cardiol Cardiovasc Interv, 2014; 7: 707-716. doi: 10.1016/j. jcin.2014.01.167.

6. Smith CR, Leon MB, Mack MJ et al.; PARTNER Trial Investigators. Transcatheter versus surgical aortic-valve replacement in high-risk patients. N Engl J Med, 2011; 364: 2187-2198. doi: 10.1056/NEJMoa1103510.

7. Adams DH, Popma JJ, Reardon MJ et al.; U.S. CoreValve Clinical Investigators. Transcatheter aortic-valve replacement with a self-expanding prosthesis. N Engl J Med, 2014; 370: 1790-1798. doi: 10.1056/NEJMoa1400590.

8. Cribier A, Durand E, Eltchaninoff H. Patient selection for TAVI in 2014: is it justified to treat low- or intermediate-risk patients? The cardiologist's view. EuroIntervention, 2014; 10 (suppl. U): U16-U21. doi: 10.4244/EIJV10SUA3.

9. Walther T, Hamm CW, Schuler G et al.; GARY Executive Board. Perioperative Results and Complications in 15,964 Transcatheter Aortic Valve Replacements: Prospective Data From the GARY Registry. J Am Coll Cardiol, 2015; 65: 2173-2180. doi: 10.1016/j. jacc.2015.03.034.

10. Duncan A, Ludman P, Banya W et al. Long-term outcomes after transcatheter aortic valve replacement in high-risk patients with severe aortic stenosis: The U.K. Transcatheter Aortic Valve Implantation Registry. J Am Coll Cardiol Cardiovasc Interv, 2015; 8: 645-653. doi: 10.1016/j.jcin.2015.01.009.

11. Holmes DR Jr, Brennan JM, Rumsfeld JS et al. STS/ACC TVT Registry. Clinical outcomes at 1 year following transcatheter aortic valve replacement. JAMA, 2015; 313: 1019-1028. doi: 10.1001/jama.2015.1474.

12. Mack MJ, Leon MB, Smith CR et al.; PARTNER 1 trial investigators. 5-year outcomes of transcatheter aortic valve replacement or surgical aortic valve replacement for high surgical risk patients with aortic stenosis (PARTNER 1): a randomized controlled trial. Lancet, 2015; 385: 2477-2484. doi: 10.1016/ S0140-6736(15)60308-7. 
13. Waksman R, Pichard AD. Will TAVR become the default treatment for patients with severe aortic stenosis?. J Am Coll Cardiol, 2015; 66: 122-124. doi: 10.1016/j.jacc.2015.05.016.

14. Barbanti M, Petronio AS, Ettori F et al. 5-year outcomes after transcatheter aortic valve implantation with CoreValve prosthesis. J Am Coll Cardiol Cardiovasc Interv, 2015; pii: S19368798(15)00698-6. doi: 10.1016/j.jcin.2015.03.024.

15. Miller DC, Blackstone EH, Mack MJ et al. Transcatheter (TAVR) versus surgical (AVR) aortic valve replacement: occurrence, hazard, risk factors, and consequences of neurologic events in the PARTNER trial. J Thorac Cardiovasc Surg, 2012; 143: 832-843. e13. doi: 10.1016/j.jtcvs.2012.01.055.

16. Bosmans J, Bleiziffer S, Gerckens U et al.; ADVANCE Study Investigators. The Incidence and Predictors of Early- and MidTerm Clinically Relevant Neurological Events After Transcatheter Aortic Valve Replacement in Real-World Patients. Am Coll Cardiol, 2015; 66: 209-217. doi: 10.1016/j.jacc.2015.05.025.

17. Sinning J et al. Personal communication. DGK 2013.

18. Athappan G, Gajulapalli RD, Sengodan P et al. Influence of transcatheter aortic valve replacement strategy and valve design on stroke after transcatheter aortic valve replacement: A metaanalysis and systematic review of literature. J Am Coll Cardiol, 2014; 63: 2101-2110. doi: 10.1016/j.jacc.2014.02.540.

19. Baumbach A, Mullen M, Brickman AM et al. Safety and performance of a novel embolic deflection device in patients undergoing transcatheter aortic valve replacement: Results from the DEFLECT I study. EuroIntervention, 2015; 11: 75-84. doi: 10.4244/EIJY15M04_01.

20. Rodés-Cabau J, Kahlert P, Neumann FJ et al. Feasibility and exploratory efficacy evaluation of the Embrella Embolic Deflector system for the prevention of cerebral emboli in patients undergoing transcatheter aortic valve replacement: The PROTAVI-C pilot study. J Am Coll Cardiol Cardiovasc Interv, 2014; 7: 1146-1155. doi: 10.1016/j.jcin.2014.04.019.

21. Circ Ghanem A1, Kocurek J, Sinning JM et al. Cognitive trajectory after transcatheter aortic valve implantation. Cardiovasc Interv, 2013; 6: 615-624. doi: 10.1161/CIRCINTERVENTIONS.112.000429.
22. Nazif TM, Dizon JM, Hahn RT et al.; PARTNER Publications Office. Predictors and clinical outcomes of permanent pacemaker implantation after transcatheter aortic valve replacement: the PARTNER (Placement of AoRtic TraNscathetER Valves) trial and registry. J Am Coll Cardiol Cardiovasc Interv, 2015; 8 (1 Part A): 60-69. doi: 10.1016/j.jcin.2014.07.022.

23. Babaliaros V, Devireddy C, Lerakis S et al. Comparison of transfemoral transcatheter aortic valve replacement performed in the catheterization laboratory (minimalist approach) versus hybrid operating room (standard approach): Outcomes and cost analysis. ACC Cardiovasc Interv, 2014; 7: 898-904. doi: 10.1016/j. jcin.2014.04.005.

24. Petronio AS, Giannini C, De Carlo M et al. Anaesthetic management of transcatheter aortic valve implantation: Results from the Italian CoreValve registry. EuroIntervention, 2015; 10: 20140605-02. doi: 10.4244/EIJY15M03_05.

25. Kodali S, Pibarot P, Douglas PS et al. Paravalvular regurgitation after transcatheter aortic valve replacement with the Edwards sapien valve in the PARTNER trial: Characterizing patients and impact on outcomes. Eur Heart J, 2015; 36: 449-456. doi: 10.1093/eurheartj/ehu384.

26. Van Belle E, Juthier F, Susen S et al.; FRANCE 2 Investigators. Postprocedural aortic regurgitation in balloon-expandable and self-expandable transcatheter aortic valve replacement procedures: analysis of predictors and impact on long-term mortality: Insights from the FRANCE2 Registry. Circulation, 2014; 129: 1415-1427. doi: 10.1161/CIRCULATIONAHA.113.002677.

27. Williams M, Kodali SK, Hahn RT et al. Sex-related differences in outcomes after transcatheter or surgical aortic valve replacement in patients with severe aortic stenosis: Insights from the PARTNER Trial (Placement of Aortic Transcatheter Valve). J Am Coll Cardiol, 2014; 63: 1522-1528. doi: 10.1016/j.jacc.2014.01.036.

28. Barbanti M, Webb JG, Hahn RT et al. Impact of preoperative moderate/severe mitral regurgitation on 2-year outcome after transcatheter and surgical aortic valve replacement: Insight from the Placement of Aortic Transcatheter Valve (PARTNER) Trial Cohort A. Circulation, 2013; 128: 2776-2784. doi: 10.1161/CIRCULATIONAHA.113.003885. 